\title{
Analysis and Development Forecast of O2C Model
}

\author{
Wenrong Jiang \\ The School of Computer and Information, Shanghai polytechnic University, Shanghai, China \\ wriiang@sspu.edu.com
}

\begin{abstract}
O2C English can name office to the customer can be interpreted as enterprise customers on hand for customized services. At the same time $\mathrm{O} 2 \mathrm{C}$ English can also be full name online configuration, translation online configuration mode of electronic business affairs, its meaning is the customized products from the store moved to the Internet, by app or web online platform to implement the product sales configuration, such as cabinets, wardrobe and other furniture products. This paper mainly introduces the burning van Persie, good cook this two big Chinese custom platform, and this platform is a typical analysis of the A class of $\mathrm{O} 2 \mathrm{C}$ platforms is currently in the environment and new direction.
\end{abstract}

\section{Introduction}

$\mathrm{O} 2 \mathrm{C}$ mode is in foreign countries has been very popular, but in China is still in the continuous exploration of new e-commerce model. In good cook, cooking rice, etc. all the $\mathrm{O} 2 \mathrm{C}$ catering customization platform, herding behavior of Chinese people on online shopping started signs, the industry to meet the a good momentum of development, but although the $\mathrm{O} 2 \mathrm{C}$ mode is popular, but generate profits is relatively low, so many companies can not accept such consumption patterns. Especially logistics problems, to food products not easy to implement, so the industry still exist many problems still need to industry leaders and successor not Exploration and practice.

\section{Two platform's profile}

"Cook the meal" is Recommended outsourcing the earliest cooking rice of "life" is somewhat complex, which the parent company the Lord do app development and operation service started, once for KFC, pizza hut, UNIQLO development and operations over the official app. After the second transition to do the shopping platform "good things" and found that the color is not in the beginning of the end of the third transformation, "cooking rice" is the third "toss" product. Cooking meal service is only limited to the Shanghai area, the daily orders more than 200 , the peak 300 single. Signing the chef, was still in the training, a single daily cooks after 2 single, belonging to a still in the continuous development of beauty.

Van Persie home cook smashing cast is to rely on to survive but in October 13, home cooks "cooking rice" users received from its founder Zhang Zhijian of a letter of farewell letter, once billed to start the fourth kind of meal pattern "cooking rice in the 11 months after declared closed transformation. Some people say o2o start-up companies in the initial stage of burn to the development, many companies because did not survive the winter capital closed their doors, but Lei Junlian 3 out of o2o" cooking rice "is not short of money. In the burning van Persie founder to the user of a letter, said Zhang Zhijian: very sorry, after 11 months of effort, we do not have the ability to burn Become a profit model is clear, and can scale expansion of the business.

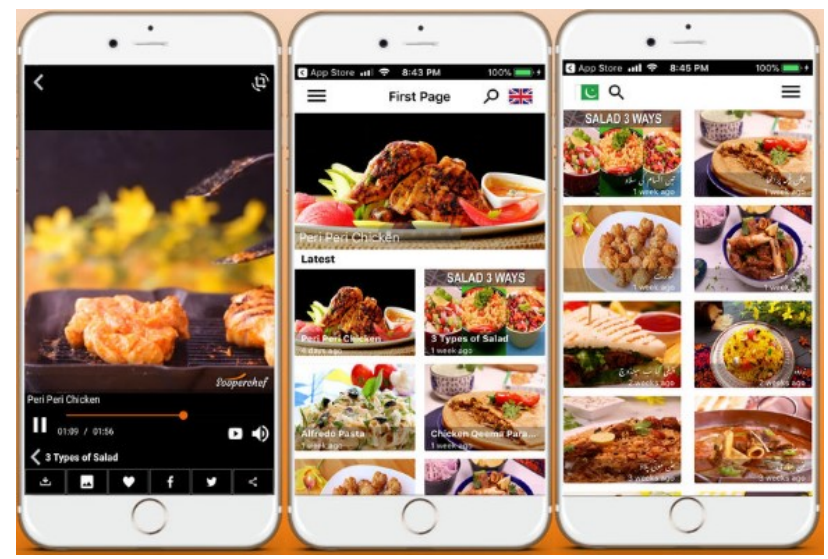

Figure 1. Cook Rice Online application

Good cook app launched in June 2014, get road capital 500 million yuan Angel round of financing in October 2014, 2015 in February at the speed of light an Zhen completed on 8 good cook a round of $\$ 500$ million investment.2015 chef home platform good cook announced that has completed 100 million RMB B round of funding, led by Cowin investment. According to the good cook CEO Xu Zhiyan: B round of financing in fact before the last month has been completed, the company 
of the current round of financing to expand the size of the market, and in 2015 opened dozens of second tier cities, expansion while continuing to services standardization, continue on the line More categories, more personalized packages to meet consumer demand.

A good cook to his first defined as a service company, do is service and quality, then an Internet company, combine is the use of the Internet to the traditional service quantitative. Good cook said, to cook in the next step will come up with a large amount of subsidies to encourage outstanding chef, and ultimately more pay for more work, the chef's overall service can continue to improve.

(2) ${ }_{\text {OOD }}$ CHEF

\section{DISCOVER}
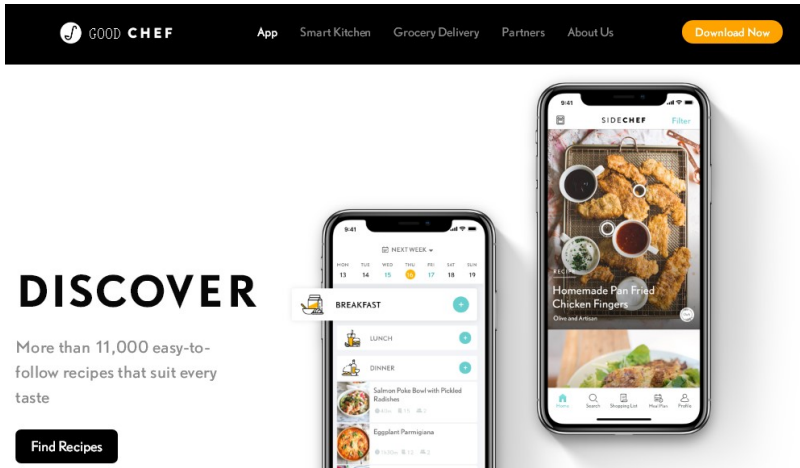

Figure 2. Good Cook Online application

\section{Business model of the two platforms}

Good cuisine and Sichuan cuisine chef of entrepreneurship, and in fact, from the beginning of this year to provide private kitchen, "the direction of entrepreneurial people up, gambling is people's future life will leave on door-to-door service can let oneself from the kitchen liberated chefs. And the two companies" good cook "," cooking rice "is one of the leaders, they provide is the booking door-to-door service products. Open the app, users can according to their own want to choose to be a chef, such as you are more preference, and the Hunan cuisine, the cuisine, Shandong cuisine, and so on. Selected, the user can according to the category to show cook dishes, and ultimately selected chefs. And then make an appointment to the time of a chef's door service, need to do a number of dishes and whether or not to buy food.

when each point can provide the standard of service, the future of this platform is possible, will not happen in the scale of the quality of the control is not good, causing negative events such as users.

Out front as far as possible to train in order to let the chef to stick to the user, the above mentioned "good cook" will be through the establishment of a line of chef, chef service standards, then cook to how the service can let users on the platform have a favorable impression? Generally speaking, these cooks at home when it has systemic dress well in the door (first impressions), and in half an hour to put all the dishes prepared and swing disc (similar to the hotel to the pendulum disk), and back to the user. When the user to prepare a good meal, a chef will prepare good Bonus gift (such as imported ice cream, etc.), to the user a surprise. When these processes are After the completion, the chef will leave, and then the platform will be a certain way to ask the user for the evaluation of the service.

Little chef at chef cooperation will the cooks in the preparation process and user communication, if the user home for the elderly or children, the chef who will design nutritious meals to meet these particular populations. The platform model and working chefs, cooks, and users of the docking platform, do a good job in the user's service and control. In addition to the healthy card, working chefs and other necessary barriers to entry management, cooking rice platform settled before and after each stage, will cook training. The cooking rice platform for 30 years or so, generally 10 years Chef experience. Males accounted for $90 \%$, the professional feature is apparent, the words within the majority. it is characteristic of such professional groups with training meal burn control, can achieve the quality of service guarantee.

\section{Profit model}

In finished them into the bulk of the charges are good cooks present on the user's four dishes and one soup, 79 yuan, six dishes and one soup 99 yuan, if is a full-time chef, they will take the income of all attributable to cook, and if is a part-time chef, each person will smoke into 9 yuan. But the service fees and not their expected future earnings, the chef is a user's home in the "entrance", the future more imagination space. For example, now with a meal giveaway of imported ice cream, there are many users will ask is what brand, where to buy? So the future with a meal of goods and services have the opportunity to follow the cook together into the user's home.

"Good cook" team in September this year, was formally established, currently covers only the Shanghai area, existing IOS application. We reported before "love Chef" product form and a good cook is similar, but in the front end and back end are different, such as product level at present love chef has been able to see user comments and reply, the embryonic form of the community, and good chef app active is little, also backend love chef tend to platform, but the good cook will be heavier.

And "cooking the meal," the payment mode is also very interesting. It allows the user to a single purchase, but were more likely to in the user to the cook formed good impression after allowing users to purchase a membership to recharge, and single dispersed users into long-term users. Before the fact, $I$ in the trial of this service obviously feel the less demand, if the user needs of its frequency is not high, may for a long period of time, they will happen again the second purchase, the membership I think should be the good way.

\section{Two platform competitive Strength}

Eat, is definitely a priority for the Chinese people, all users have to Aunt home cooking with strong demand, but domestic companies definitely meet they do not. The 
two platform first found not a chef home enterprises, they took the lead in the first on-line account for the pit, so days later when investors take the relatively smooth, set up the team. The advantage is in July to get the first round of financing, at present, service users have more than 140000 , the members are stored value is in three thousand and opened in Beijing, Shanghai, Hangzhou, now cooperation cook for thousands of people. In less than a year of time, completed the fourth round of financing.

While cooking rice network in December 2014 obtained by IDG capital and Lei [microblogging]'s shun a capital investment of $\$ 150$ million $C$ round, three rounds of financing amounted to $\$ 833$ million. 11 months operation of products, condensed the love of more than 20 million users with more than 700 professional chef and more than 30 entrepreneurial small partners sweat. The two companies undoubtedly in the capital operation first prize.

\section{Two platform's Weakness}

For this type of platform is the biggest problem is not to find a clear profit and scale expansion of the business model. From the point of view of "cooking rice, mature clear commercial pattern is decided the door key to the success or failure of the o2o. Home cuisine CEO SUN Hao said:" industry does not want to see the prisoner's dilemma situation, resources should not be wasted in guessing each other and fear of competing products strategy. "SUN Hao stressed that the duopoly is catering o2o industry evolution of optimal shape, industry to the venture full opportunity to come to the fore, and really good service, is done in a healthy competitive environment evolution.

No difference, no user loyalty, the industry will not leave a real asset. The next step is to adhere to the path of differentiation, focus on details, adhere to the early heart, good service, to provide users with better dining scene services. For large kitchen door how to break out of the problem, the industry has said that in the back of the game should also have more differences.

Each burn out Zhang Zhijian thinks, now most of the collapse of $\mathrm{o} 2 \mathrm{o}$ business company a is a common problem in the burn burned the wrong place. "Cooking rice" is the same, the money to burn in the superficial, and did not use the money to build their own core competitiveness, for their own long-term development of the road. As the saying goes, good steel should be used in the blade, although 020 industry in burn money, but the money spent on where also determines the road can go far. To find the real pain, find strong demand, is the home of o2o first to clear direction. But for pain points is not easy Zhang Zhijian said: "the door to burn rice is actually a little pain, but also there is a demand, but the pain and Users can not let the pain, the demand is not strong enough to let users rely on. Find the user's real pain point, strong demand to find their core business, to find their own to coordinate the part of the resources, the industry chain to have control and power to form a scalable model.

Easy 'occupy the home o2o to want to survive, we need from the existing users find their real users, the difference in service to increase user stickiness. Period, a large number of subsidies in the form of market business model is the fundamental for entrepreneurs. "Cook rice' closed transformation after the taste buds' in order to survive, to the real users do more precise targeting of services. After all, to live long, length ratio were on the verge of important." find a little pain, but let the pain becomes profitable difficult. Lock which resources, grasping what demand, mode quicker is fundamental. If the pattern began to pack a lot, but not bad.

\section{Two platform's opportunity}

A report from the China Cuisine Association shows that in 2014 the national food industry revenue was 2.786 yuan, is expected in 2015 will reach 3000000000000 yuan.2014 (including takeaway door, buy coupons, home cooking, etc.) market size increased by $51.8 \%$ to 951 yuan, 2014 catering $\mathrm{O} 2 \mathrm{O}$ online users grew by $38.5 \%$, significantly higher than the national food and beverage revenue growth is expected in $2015 \mathrm{O} 2 \mathrm{O}$ market size and online users will be more than $30 \%$ to 1300 yuan and 2.2 people.

$\mathrm{Xu}$ Zhiyan for the demand in general, this industry there are three opportunities. One is from consumers and ordinary family every day to eat, and seize the consumer preferences share characteristics; second is from the chef, chef industry income level is relatively low, the daily workload, and a good cook cooks provides a best platform. According to CEO, said to the current orders, cook every day to pick up three single, noon, evening two single day do 18 dish of income can be maintained in the 8000 yuan, easily earn than the original or even more times income; the third is the social influence, private kitchen door for consumers to provide a kind of new Way of life, and do not lose in the home to eat a warm feeling, more than one stroke.

\section{Two platform's Threat}

The rice cooking design business model, CEO Zhang Zhijian firmly choose the "Taobao" platform mode, he thinks "Jingdong" self mode in the home cook o2o project is not sustainable. "We do not employ any full-time chef, because when one day, at the date of the order up to 1 million, to maintain high efficiency, a chef processing a single, need to recruit million people, which for a start-up company is not economical and unreasonable." Zhang Zhijian also said, "full-time chef and our employment relationship is working attitude. Part-time cook is different, their own in the use of burning van Persie platform business, dynamic the home cooking service to do a good job, establish a good reputation. We hold the attitude of open platform, the chef can be as free as the Uber driver "

Insiders said that with mobile payment scenarios of expanding, life service of $\mathrm{o} 2 \mathrm{o}$ is constantly infiltration and transformation of various types of segments of life service market. "Entrepreneurial minority only see home situation $\mathrm{o} 2 \mathrm{o}$ fiery unwilling to remain out of the limelight." the source said from early to call to order 
takeout, and later the PC, mobile terminal, takeaway has high frequency, but before o2o D-Will, chef home cooking has not been the norm.

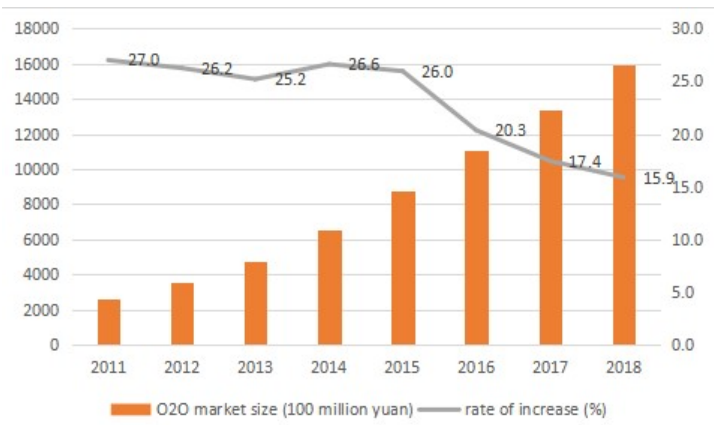

Figure 3. o2o market analysis in China

Chef of the door to door service o2o ends of supply and demand is not balanced, for example, when dinner need a chef of the door to door service, often need a lot of chef. This is often hotel is the most busy time, cooks very difficult to go to do a part-time job. This makes no sufficient number of chefs to meet user demand, resulting in both supply and demand is out of balance. From the concrete operational level, the chef also need equipment and tools, part of the hotel chef is not suitable for in home to do the ordinary food.

Chef of the door to door service o2o another obstacle is, meal also belongs to non standardized products, for example, a dish 9 people say the food is delicious, but also has a person that can not say. Eventually, the chef of the door to door service o2o also face difficult to cater for all tastes of embarrassment. In this series of factors, put aside "Internet + , o2o shared economic, drops of food industry" the fetters of the normal thinking buzzword, back to the pioneering early heart is to settle down in this.

\section{Future development forecast of Chinese custom platform}

This field service in 020 concept after the rise of certain trendency hot door, a variety of services industry scramble to catch the express door-to-door service. Because the market is hot, "service + home" situation is appropriate is ultimately not awake for a couple of people see, as long as the concept of blowing good, the investor's money will soon hand, with subsidies and other means to gradually stop, the market will eventually return to calm. When the door service sector will usher in a stormy baptism, can foresee future mortality of door-to-door service categories will be more and more, this is the choice of the market, and consumer choice. After the ebb tide, left is the real For the genes of the Internet service industry, those who try to ride the, playing the subversion of service industry finally fear or gods reparations bale.
Good cook, cook rice, chef home o2o project of the better known Xianfeng Huaxing and Gao Rong, Datai of millions of dollars in investment projects in Beijing love chef.O2O entrepreneurial hot rise, similar to the "good service" business like a rising wind and scudding clouds, but the feelings of feelings and business students meaning. Venture will eventually return to the business nature of: profit oriented, clearly scale profit model. For the catering business, central kitchen, a single product explosion models, much food distribution, raw and semi-finished products distribution, is catering $02 \mathrm{o}$ future direction.

\section{Acknowledgement}

This work is supported by the Key Disciplines of Computer Science and Technology of Shanghai Polytechnic University under Grant No. XXKZD1604.

\section{References}

1. Wenrong Jiang, Yingyan Liu. Analysis of the double 11 ouyeel business promotion effectiveness [C]. 2016 ISSGBM International Conference on Information, Communication and Social Sciences (ISSGBM-ICS 2016), Dubai, United Arab Emirates, Singapore Management and Sports Science Institute, October 8, 2016, 49-55. WOS:000391774900010.

2. Zhu Huabing, Gong Jianghong. Analysis of the impact of the financial crisis on the foreign trade of Zhejiang [J]. Commercial era, 2010(7): P129-131.

3. Wenrong Jiang. Analysis and Research on Failure Reasons of NOKIA [J]. Lecture Notes in Management Scient. Vol.94. 2018 6th International Conference on Physical Education and Society Management (ICPESM 2018), London, UK, Singapore Management and Sports Science Institure. July 22-24, 2018, 290-295.

4. Wenrong Jiang, Shiwei Li. Analysis of Xiaomi Tech's E-commerce model [J]. 2nd International conference on E-commerce and Contemporary Economic Development (ECED 2015), Nanjing, China, December 5-6, 2015, DEStech Publications, Inc. 196-200. WOS:000380277700040.

5. Wenrong Jiang, Jian Chen. Traditional Enterprises Transformation and Strategy to Deal with ECommerce [J]. 2015 4th International Conference on Physical Education and Society Management (ICPESM 2015), Singapore, December 6-7, 2015, Lecture Notes in Management Science, 2015 (12), Vol 47, 301-306. IDS No.: BF3BX.

6. Wenrong Jiang. Analysis the $\mathrm{O} 2 \mathrm{O}$ marketing model about old network website [J]. The Second International Conference on Economic and Business Management (FEBM2017), Shanghai, China, ATLANTIS Press. October 21-23, 2017, 507-512. 